Revue bibliographique pour le domaine irano-aryen

\title{
Markus Ritter. "The Kashan Mihrab in Berlin: a Historiography of Persian Lustreware"
}

\section{Anaïs Leone}

\section{(2) OpenEdition \\ 1 Journals}

\section{Édition électronique}

URL : http://journals.openedition.org/abstractairanica/49598

DOI : 10.4000/abstractairanica.49598

ISBN : 1961-960X

ISSN : 1961-960X

Éditeur :

CNRS (UMR 7528 Mondes iraniens et indiens), Éditions de l'IFRI

Référence électronique

Anaïs Leone, " Markus Ritter. "The Kashan Mihrab in Berlin: a Historiography of Persian Lustreware" », Abstracta Iranica [En ligne], Volume 40-41 | 2019, document 12, mis en ligne le 30 octobre 2019, consulté le 20 avril 2021. URL : http://journals.openedition.org/abstractairanica/49598 ; DOI : https:// doi.org/10.4000/abstractairanica.49598

Ce document a été généré automatiquement le 20 avril 2021.

Tous droits réservés 


\title{
Markus Ritter. "The Kashan Mihrab in Berlin: a Historiography of Persian Lustreware"
}

\author{
Anaïs Leone
}

\section{RÉFÉRENCE}

Markus Ritter. "The Kashan Mihrab in Berlin: a Historiography of Persian Lustreware" in Yuka Kadoi (ed.). Persian Art: Image-Making in Eurasia. Edinbourg : Edinburg University Press, 2018, p. 157-178

Daté 623/1226 et signé du nom d'al-Ḥasan ebn 'Arabshāh, le mihrab aujourd'hui conservé à Berlin constitue un véritable jalon dans l'histoire de la céramique lustrée de l'Iran médiéval. Markus Ritter retrace le tumultueux parcours de cette pièce, depuis les murs de la Masjed-e Maydān à Kāshān jusqu'à sa présentation au musée d'art islamique de Berlin, en passant par la prestigieuse collection d'art persan de Sir William Preece en Angleterre. En se détachant des plus classiques investigations sur le contexte de production, il propose ici une lecture plus historiographique de l'œuvre. L'auteur analyse la réception de ce mihrab dans le contexte européen de la fin du XIX ${ }^{e}$ siècle : après une présentation des sources anciennes et modernes, il retrace, souvent avec un degré de précision remarquable, les étapes clés de ce voyage ponctué de restaurations. Ritter entend mettre ainsi en lumière l'impact du mihrab de Berlin, et plus largement des revêtements lustrés, à leur arrivée dans les collections et sur le marché de l'art occidental. Parallèlement, la publication de ces pièces a contribué à alimenter le discours sur l'art persan qui se façonne à la même période, notamment dans le Survey of Persian Art édité par A. U. Pope (1938). La céramique lustrée est considérée dans cet ouvrage comme la technique la plus à même d'exprimer les qualités esthétiques et techniques de cet art. Au centre de cet exposé, le mihrab de Berlin, reproduit en pleine page et en couleur, illustre cette idée autant qu'il la modèle à sa propre image. Finalement, l'article de Ritter nous invite à une certaine prudence méthodologique vis- 
à-vis de pièces célèbres, voire emblématiques, en gardant à l'esprit qu'elles ne sont pas toujours représentatives de la totalité des artéfacts issus d'un même contexte de production.

\section{AUTEURS}

\section{ANAIIS LEONE}

Doctorante, Aix-Marseille Université/LA3M 